\title{
El pensamiento político de Hannah Arendt: notas sobre revolución, promesa y fundación política
}

\author{
Hannah Arendt's political thought: notes on revolution, promise \\ and political foundation
}

\author{
Julia Gabriela Smola \\ jsmola@ungs.edu.ar \\ (Universidad Nacional de General Sarmiento, Buenos Aires, Argentina)
}

\begin{abstract}
Resumen: Presentaremos aquí una lectura de Sobre la revolución para poner en valor la tarea crítica sobre los conceptos políticos de la tradición en la elaboración de una teoría política propia de gran originalidad. Primero, analizaremos las dificultades metodológicas y contextuales del libro. Segundo, analizaremos el trabajo de renovación de ciertos conceptos políticos claves para la idea de promesa mutua (su mayor innovación conceptual). Luego, reflexionaremos sobre el tipo de instituciones que piensa Arendt en torno a la fundación de la libertad en el mundo contemporáneo. Finalmente, ofreceremos algunas conclusiones que se desprenden de nuestra lectura del texto.
\end{abstract}

Palabras clave: Hannah Arendt; revolución; promesa; fundación; teoría política.

\begin{abstract}
We shall present here an interpretation of On revolution that reveals the critical review of traditional political concepts the author makes while she elaborates her own original political thought. First, we will analyze the methodological and contextual difficulties of this book. Secondly, we will analyze her work on the renewal of certain key political concepts related with the idea of mutual promise (her most important innovation). Then, we shall reflect on the type of institutions she considers for modern political foundation. Finally, we will offer some conclusions that derive from our own reading of this text.
\end{abstract}

Keywords: Hannah Arendt; revolution; promise; foundation; political theory.

DOI: http://dx.doi.org/10.11606/issn.2318-9800.v21i3p93-110

\section{La difícil lectura de Sobre la revolución}

La lectura de Sobre la revolución siempre ha representado un desafío para los lectores de la obra de Hannah Arendt. Como expresa Margaret Canovan, es su texto "menos valorado [y] menos leído" (Canovan, 1992, p.155). Sus dificultades no difieren de las condiciones generales de sus textos, el contexto de surgimiento (plena guerra fría), la incomodidad de su posición política en el tradicional espectro de izquierda y derecha, su operación de pensamiento (a la vez contra la tradición de la filosofía política y contra las ciencias sociales) ${ }^{1}$. A las complejidades de lectura

1 La bibliografía que ha sido dedicada a la compleja relación de Hannah Arendt con la filosofía es frondosa. En particular, tomamos como referencia para abordar este tema el texto de Miguel Abensour (2006) quien, de manera muy pertinente, pone en duda que Arendt esté contra la filosofía política e insiste en el valor de explorar esta relación. Asimismo, nos guiamos por la idea desarrollada por Paula Hunziker (2015), quien sostiene que aquello que Arendt rechaza de plano en la tradición 
a la que nos tiene habituados la autora, se agrega, en esta obra, el hecho de que la misma es

un especie de híbrido. Inspirado, en parte, por acontecimientos específicos, pero que [a la vez] une con el hilo de las revoluciones muchas líneas de reflexiones originadas en la experiencia del totalitarismo, y que informaron el proyecto inconcluso de Arendt sobre la renovación del pensamiento político (ídem, ibídem).

Sin embargo, también es cierto que, para Arendt, ambas operaciones, "ejercicios de pensamiento" como los llama, deben permanecer juntas si se quiere evitar caer en el solipsismo teórico y apartarse irremediablemente del mundo. Si abrazamos esta complejidad en lugar de intentar combatirla, si comprendemos que las operaciones arendtianas siempre involucran este tipo de combinaciones, si dejamos de intentar leer el libro como un ensayo histórico o como un texto teórico ${ }^{2}$, podemos comenzar a dimensionar su importancia. En este sentido, compartimos con Margaret Canovan que la misma sale a la luz de manera privilegiada, si pensamos a esta obra, no solo ni exclusivamente en línea directa con la teoría de la acción que se desprende de La Condición Humana (1958), sino con la serie de preocupaciones que animaron el pensamiento de Arendt desde la escritura de Los Orígenes del Totalitarismo (1951). En este sentido, la preocupación que reaparece en Sobre la Revolución (1963) no sería simplemente, “¿cómo (dentro de qué límites) la acción política es capaz de fundar un cuerpo político organizado?”, “¿qué capacidades humanas son las que permiten legitimar la fundación política moderna?”, sino más precisamente, “¿cómo es posible fundar un cuerpo político en un mundo postotalitario?”, “¿qué formas debe asumir para intentar preservar la libertad?". Siguiendo lo que Canovan llama las cadenas de pensamiento o de ideas que inspiran la obra de Arendt vemos que todas las cuestiones relativas al problema de la fundación política moderna-la revolución, el problema del absoluto, del comienzo de los tiempos, de la preservación del espacio de la acción- toman otra dimensión en el telón de fondo del nazismo y del estalinismo. Así, no se trata ya de ver qué revolución moderna fue la más "exitosa" o qué “modelo" es preferible, ya que, por un lado, ambas revoluciones fracasaron y, si pudieran modelizarse (creo que nada está más lejos de la intención de Arendt), se vería que ambos “modelos", en tanto tales, son inadecuados para responder a las

de la filosofía política es una cierta "actitud" hacia la política y hacia el mundo que la autora caracteriza como platonismo.

2 En este mismo sentido, Anabella Di Pego propone realizar "dos movimientos complementarios en la lectura de Hannah Arendt. Por un lado, [llevar] a cabo una lectura filosófica de Los orígenes del totalitarismo [1951], y, por otro lado, [emprender] una historización y una contextualización de La condición humana [1958]" (Di Pego, 2014, p.29). De esta forma, la autora invierte las claves de lectura tradicionales con que se ha abordado estas obras de Arendt abriendo a una nueva, más compleja y más profunda comprensión de ambos textos, así como de la relación entre ellos. Creemos, como propone De Pego, que los textos de Arendt exigen a la vez una comprensión filosófica y una contextualización e historización de las problemáticas que las inspiran; y esto vale, por supuesto, también para Sobre la revolución. 
preocupaciones de la autora. Mucho más importante, para Arendt, es aprehender las experiencias de las revoluciones modernas a través de un lenguaje teórico-político renovado, es decir, a través de la resignificación de los conceptos políticos. Esta es la tarea que Arendt asume en esta obra con el objetivo último (in the back of her mind) de pensar, como decíamos más arriba, si la fundación de un cuerpo político libre es posible en nuestro mundo contemporáneo. ${ }^{3}$

Debido a esta serie de complejidades intrínsecas y contextuales, la recepción de este libro en nuestros países y en aquellos países que constituyen en gran medida nuestra referencia intelectual y académica, ha sido dificultosa. Como señala Claude Lefort (1985), las primeras lecturas de la obra de Arendt en Francia estuvieron mediadas por el rol de Raymond Aron en la introducción de sus libros al público francés. De esta forma, su primera recepción fue preponderantemente liberal e ignorada, cuando no directamente denostada por la izquierda intelectual francesa, que en ese momento se encontraba bajo la impronta del marxismo. Esto condujo a que ciertos tópicos de la autora fueran ignorados al no encontrar lectores que pudieran interesarse en ellos. Lefort remarca uno de gran importancia: el interés de Arendt por la revolución, no como un simple objeto de curiosidad intelectual, sino como el "tiempo del comienzo o del recomienzo" (Lefort, 1985, p.64, nuestras cursivas). ${ }^{4}$

Según el autor, el cambio de época vivido en Francia hacia fines de los setenta

3 La expresión in the back of my mind es utilizada por Arendt en la entrevista televisiva con Günther Gaus en 1963 para referirse a los poemas alemanes que ella atesora y guarda siempre en su mente. En la transcripción de la conversación entre Arendt y Gaus, que fue publicada bajo el título "Sólo queda la lengua materna" (Arendt, 1997, pp.221-256), la autora se refiere también a su necesidad de comprender. Esa necesidad la impulsó hacia la filosofía y es la que motoriza todas sus investigaciones. No creemos estar traicionando la idea de la autora cuando hacemos referencia a las preguntas o preocupaciones que subyacen a su obra. No estamos sosteniendo que para Arendt se trate de pensar "el mejor régimen" como lo abordaría tradicionalmente la teoría política. Más bien de concebir una teoría política que pueda pensar, que ayude a comprender, el mundo postotalitario.

4 Como recuerda Elizabeth Young-Bruehl (1982) en la biografía de Arendt, la recepción de sus ideas en Francia fue muy difícil debido al debate intelectual de aquellos años. Arendt misma da cuenta de esa dificultad en sus cartas a Blücher en donde explica que los intelectuales franceses "Están completamente envueltos en sus teorías y viven en un mundo organizado de manera hegeliana" (Carta de Arendt a Blücher del 24 de abril de 1952, citado por Young-Bruehl, 1999, p.365). Arendt vierte sus impresiones sobre la intelectualidad francesa de posguerra en un texto presentado ante la Asociación americana de ciencias políticas titulado "Concern with politics in recent European thought" que Young-Bruehl transcribe en la biografía: "Debido al carácter ilusorio de toda solución surgida de su propia filosofía, Sartre y Merleau-Ponty no pueden sino adoptar el marxismo, superponerlo de alguna forma a su marco de referencia para la acción, aunque su pensamiento original no deba nada al marxismo. No debe sorprender que, una vez que han salido del impasse del nihilismo por medio de argumentos que en el fondo son idénticos, se separen para adoptar posiciones finalmente diferentes en la escena política; en el campo de la acción, todo se vuelve enteramente arbitrario, siempre y cuando prometa un cambio revolucionario." (ídem, p.366). Como sostiene Young-Bruehl, aunque la crítica de Arendt es profunda y enmarca a la filosofía política francesa de posguerra con la tradición en el sentido preciso que acabamos de citar, también reconoce en ella el interés que despliega por la acción, la rebelión y la revolución. Una atención que, según Arendt, se revela contra las "viejas sospechas de los filósofos" (ídem, ibídem). 
y durante los primeros años ochenta lleva aparejado cierto desencantamiento con las lecturas en clave marxista, donde nuevas preguntas surgen con fuerza mientras que viejas cuestiones se hacen más difusas. Así, cierta crítica del racionalismo llevó al cuestionamiento no sólo de la filosofía iluminista sino también de la filosofía de la historia, y de la noción de historia como dadora de sentido, es decir, mediante la cual accedemos a nuestro pasado. Estas posiciones encuentran su reflejo en la crítica del Estado, considerado como órgano de homogeneización de lo social y de dominación, que acrecienta su fuerza como efecto de la demanda de satisfacción de las necesidades colectivas (ídem, ibídem). En este contexto, la crítica a todo aquello que fuera del orden de la violencia y la invitación a no confundir la política con esta última, hizo que la obra de Arendt tomara importancia y se leyera, no ya únicamente en los círculos liberales, sino por pensadores de otras tradiciones. En este sentido, sus lecturas fueron movilizadas en la crítica al estalinismo y en la revalorización de la democracia como régimen político frente al totalitarismo.

Así, Claude Lefort y Cornelius Castoriadis leyeron atentamente Los Origenes del Totalitarismo para desarrollar su propia crítica a los regímenes totalitarios. Lefort se interesó particularmente por el concepto de lo político, que, según él y en línea con el prefacio de Paul Ricoeur a la edición francesa de La Condición Humana, es desarrollado como contracara de la imagen del totalitarismo (Ricouer, [1983] 1994, p.71). Por su parte, Miguel Abensour remarca el rol que Arendt juega en el retorno de las cosas políticas al espacio intelectual francés, destacando la advertencia arendtiana de no confundir este retorno con el de la filosofía política, siendo que el regreso de esta última puede producir el paradojal ocultamiento de las primeras.

Un poco más adelante, durante los años 1990 y 2000, el estudio de la obra de Arendt proliferó en Francia y otra generación de autores como Martine Leibovici, Etienne Tassin, Françoise Collin tomaron el pensamiento de Arendt para abordar los nuevos problemas políticos de Francia y de Europa. Como señala Simona Forti (2001), se trata de la segunda ola de recepción de la obra arendtiana, en donde su pensamiento es a la vez estudiado por su valor, complejizado y movilizado para pensar de otra forma los conflictos políticos y los procesos de ciudadanía en Europa. Así, los conceptos arendtianos del derecho a tener derechos, de la desobediencia civil, y una interpretación en clave conflictual de su teoría de la acción cobraron importancia para estas lecturas que, a su vez, retomaron la crítica arendtiana al Estado-nación y a los derechos humanos elaborada en su análisis sobre Los orígenes del totalitarismo.

Estas lecturas, desde los años 1980 en adelante, son de gran interés puesto que revelan una dimensión conflictual en la obra de Arendt, que las lecturas anteriores dejaban de lado, remarcando los aportes de Arendt a una teoría de la acción política que contribuye a comprender y a la vez problematizar el actuar colectivo y la 
visibilidad del espacio público democrático. Como contracara a dicho interés por el carácter disruptivo de la acción, es puesta en valor la crítica que Arendt realiza al Estado moderno, a la teoría política sobre la que se sostiene (la teoría de la soberanía) y al sistema político que la expresa (la democracia de masas y el sistema de partidos). Así, los franceses han leído y leen en Sobre la revolución el interés crítico de Arendt por la modernidad. Ven allí una clara respuesta a la supuesta "grecomanía” arendtiana (acusación expresada, entre otros, por Habermas, 1977; y que desmiente con vehemencia Taminiaux, 2001), que desembocaría en su supuesto clasicismo o en su modernismo "reluctante" (Benhabib, 2000). Sin lugar a dudas, las lecturas francesas se preocuparon por marcar la importancia de su ensayo Sobre la revolución para la comprensión y el interés que Arendt despliega sobre los fenómenos modernos. Es el escenario que abren las revoluciones modernas y no una supuesta añoranza por la vida en la polis lo que interesa a la autora, y la piedra angular de su teoría política. En efecto, la hipótesis de lectura que han desarrollado en general los franceses, siguiendo la interpretación de Paul Ricoeur, es que fue la confrontación con los efectos devastadores de la política moderna en los totalitarismos lo que llevó a Arendt a abordar los problemas de la política contemporánea y desarrollar un pensamiento que se distinguiera de la teoría de la soberanía buscando su inspiración en el acontecimiento inaugural de la modernidad, es decir, las revoluciones francesa y americana. Así leen la continuidad de preocupaciones que llevó a Arendt a escribir Los orígenes del totalitarismo, La condición Humana y Sobre la revolución.

La lectura de Sobre la revolución que movilizan estos autores franceses se centra, entonces, en dos aspectos: por un lado, como señalamos, en la modernidad de Arendt; por el otro, en aquello que caracteriza su crítica de la modernidad, es decir, la crítica a la teoría de la soberanía. Un ejemplo claro de esta interpretación se encuentra en el texto que Tassin dedicó al encuentro en París sobre el centenario del nacimiento de Arendt: “Le peuple ne veut pas" (2007) en donde el autor revisa la crítica de Arendt a la concepción rousseauniana de voluntad que se extiende por la teoría política a partir del ideario de la revolución francesa hasta las teorías contemporáneas que ligan la acción política a la intención del actor o a la voluntad del pueblo. Para Tassin, el pueblo puede actuar, es decir, ser libre, en la medida en que renuncie a la soberanía. Un pueblo actúa, es decir, ejerce su poder constituyente, sólo en cuanto es "un pueblo destituyente". 5

Por otra parte, en nuestros países de América Latina, la recepción de la obra de Arendt también mantuvo estrecha relación con los avatares políticos que convulsionaron a la región. El final de los años 1970 y 1980 fue un momento de fuerte

\footnotetext{
5 "el poder constituyente no debe nada a la voluntad y no requiere tanto de la ficción de un pueblo constituido en su voluntad soberana como de la distancia de sí, la destitución de sí, de una pluralidad actuando, a la vez y al mismo tiempo, contra el antiguo régimen y contra el nuevo que su acción, inevitablemente, hará llegar" (Tassin, 2007, p.315).
} 
debate intelectual y autocrítico de la izquierda. La lucha contra las dictaduras en términos de derechos humanos condujo al progresivo abandono del pensamiento de la revolución y a una revalorización de la democracia como régimen político (Lesgart, 2003). En ese contexto, la obra de Hannah Arendt es recuperada frecuentemente en el debate académico, intelectual y político por escritores de diversas tradiciones políticas. Claudia Bacci, en su investigación sobre las lecturas de Arendt en la Argentina, propone los siguientes cinco momentos para pensar la recuperación de Arendt durante esos años:

la transición democrática como emergencia de una nueva articulación entre derechos humanos y democracia en clave republicana; la composición normativista de la escena judicial como espacio público paradigmático a partir del Juicio a las Juntas en 1985; las reflexiones en torno a la responsabilidad y el castigo de los crímenes del terrorismo de Estado (...); las relaciones entre lo público y lo privado a partir del desenganche neoliberal entre política y economía para explicar las transformaciones de lo político; y los recientes análisis críticos de los proyectos de cambio social de los años 1960-1970 que revisaban la relación entre violencia, política y cambio social (Bacci, 2010, p.92, cursivas de la autora).

Como demuestra el exhaustivo trabajo de Bacci, la lectura de Arendt en esos años se produce al calor de los acontecimientos que van guiando el interés de sus lectores, quienes movilizan su pensamiento en particular para interrogar el nuevo significante central de los años ochenta: la democracia. Con gran influencia del pensamiento francés, Arendt ingresa al espacio público de los debates intelectuales por intermedio, por ejemplo, de lecturas lefortianas. En estos años de intenso pensamiento sobre la fundación política y en particular, sobre las posibilidades de refundación democrática, la idea de la promesa fue retomada en el debate intelectual. Bajo la impronta de la transición democrática y de la idea de pacto social que ella traía, la promesa fue leída como un pacto de asociación y como la afirmación de la voluntad popular de restablecer el Estado democrático. ${ }^{6}$ Por supuesto, esta imagen de Estado democrático fundado por un pacto de asociación se contraponía con la idea de Estado autoritario frente al cual habría habido un mero asentimiento mudo de la sociedad.

Así, en Argentina como en Francia durante los años ochenta, se recuperaban ideas arendtianas, se leían sus textos, y entre ellos, Sobre la revolución. Aquello en lo que se hacía hincapié era, a ambos lados del océano, su crítica al Estado-Nación, visto como aparato de dominación, a la que se contraponía la idea arendtiana de la acción como capacidad humana inalienable, acercándonos visiones no violentas de la expresión ciudadana en el espacio público, aún en momentos en que ese espacio no era "plenamente" democrático o lo era sólo en un sentido frágil.

6 Ver en particular Hilb (1990) y Lechner (1990). Para el desarrollo de estos temas, vuelvo a referir a Bacci (2010). 


\section{La renovación de los conceptos políticos}

En este sentido, es posible sostener hoy, cuando más de cincuenta años nos separan de su publicación, la importancia de seguir leyendo Sobre la revolución. $Y$ de hacerlo en una clave que entienda su esfuerzo de comprensión, como dice Canovan, como una tarea combinada para abordar acontecimientos históricos con una preocupación teórica o filosófico-política por la fundación de un cuerpo político moderno, específicamente, en el mundo postotalitario.

Por ende, es necesario reconocer que Sobre la revolución se inscribe en un proyecto mayor de Arendt cuyo objetivo es "repensar los conceptos políticos". Es, en este sentido, una discusión con la lectura tradicional de los conceptos políticos que “ocultan" el sentido de algunas experiencias políticas esenciales a la modernidad. Es por eso, y no por un descuido o falta de sistematicidad de la autora, que el libro es un "híbrido". Porque para Arendt, pensar los conceptos políticos separadamente de los acontecimientos no tiene sentido, y esa es justamente su crítica a la teoría política moderna: “los teóricos estaban interesados fundamentalmente en encontrar una teoría universal aplicable a toda forma de relación pública, tanto social como política, y a todo tipo de obligaciones" (Arendt, 1992, p.174) Estaban obstinados en pensar las condiciones de fundación de un orden en todo tiempo y lugar, de manera a-histórica, fuera del tiempo. Como resultado, lo que los teóricos contractualistas expresaban eran ficciones, "explicaciones ficticias de las relaciones existentes entre los miembros de una comunidad, llamada sociedad, o entre esta sociedad y su gobierno" (ídem, ibídem).

Recuperar las experiencias, identificar los conceptos políticos que "ocultan" dichas experiencias y forjar nuevos sentidos son tareas que Arendt emprende en simultáneo. Es por eso que, frecuentemente, resulta tan difícil desentramar esos conceptos de su significado tradicional, puesto que, en muchos casos, no se trata de "contraponer" un concepto a otro (Poder a Violencia; Promesa a Contrato) sino de resignificar un mismo concepto (poder, autoridad, libertad, voluntad), rescatarlo de su sentido moral, filosófico o religioso y religarlo con su sentido político. Muchas veces, esta operación se da consciente y explícitamente, y otras es pasada por alto y los conceptos son utilizados directamente en su "sentido renovado" o "político".

Todas estas operaciones se combinan, en Sobre la revolución, para leer el acto de fundación política de las revoluciones. Se analizan al mismo tiempo las experiencias, los lenguajes políticos en la que las mismas eran expresadas o traducidas, y las teorías políticas que las explicaban. Es de esta forma compleja e intricada que una de las ideas centrales de la fundación política es presentada en el texto: la idea de la promesa mutua. En el capítulo cuarto "Fundación I: constitutio libertatis", Arendt se refiere a las formas en que ambas revoluciones tuvieron que afrontar un mismo 
problema: el problema del comienzo. Arendt observa una diferencia esencial en ambas experiencias que contribuyó en un caso y obstaculizó en otro a la constitución de la libertad. Mientras que en Francia, el derrocamiento de un monarca absoluto dejaba a los hombres en carencia de autoridad suficiente como para promulgar una constitución que fuera percibida como legítima y por lo tanto fuera duradera; en América, la independencia de Inglaterra no hizo, en palaras de Arendt, que fueran arrojados a un "estado de naturaleza, [ya] que nunca, en fin, se puso en cuestión el pouvoir constituant de quienes elaboraron las constituciones de los Estados y, en su día, la Constitución de los Estados Unidos" (Arendt, 1992, p.168). Los estados americanos se encontraban organizados en cuerpos políticos autónomos, que habían sido constituidos mucho antes de la revolución por los primeros colonos a través de pactos, al momento de desembarcar en el Nuevo Mundo. Arendt lo relata de la siguiente forma:

El Pacto de Mayflower fue redactado a bordo y firmado al desembarcar. (...)sin duda los atemorizaba el llamado estado de naturaleza, el desierto inexplorado, sin límites y fronteras, así como la iniciativa sin trabas de hombres no sometidos a ninguna ley. No es sorprendente el temor (...) Lo que sí sorprende es que su temor del prójimo fuese acompañado de una confianza no menos evidente en su propio poder, no otorgado ni confirmado por nadie, ni asistido tampoco de ningún medio de violencia, para reunirse en una "cuerpo político civil" (...) mantenido unido únicamente por la fuerza de las promesas mutuas (ídem, pp.170-171, nuestras cursivas).

Esas promesas mutuas que podían ser motivadas por afectos políticamente tan peligrosos como el temor, habían tenido la fuerza suficiente como para constituir un cuerpo político y autorizar, muchos años más tarde y a través de la asociación libre de dichos cuerpos, a la Constitución del país. Fue la experiencia, entonces, "más que cualquier teoría" (Arendt, 1992, p.172) la que creó una "nueva forma de poder" que hubiera quedado oculta a nuestros ojos de no ser por el acontecimiento de la revolución, que se sostuvo sobre esta experiencia primera y que puso en valor su contenido político. Fue la teoría, más que cualquier experiencia ${ }^{7}$, la que ocultó la novedad de dicho poder bajo su lenguaje y sus exigencias normativas:

el siglo XVII distinguió en teoría entre dos tipos de «contrato social». Uno se llevaba a cabo entre individuos y daba nacimiento a la sociedad; el otro se llevaba a cabo entre el pueblo y su gobernante y daba origen al gobierno legítimo. Sin embargo, las diferencias esenciales entre estos dos tipos de contrato (que apenas tenían en común un nombre equívoco) fueron pronto olvidadas (...) de ahí que las dos posibles interpretaciones del "contrato social», las cuales, como veremos, se excluían entre sí, fuesen consideradas, con mayor o menor claridad conceptual, como aspectos de un único contrato doble. (...) En forma esquemática, se pueden enumerar del modo siguiente las principales diferencias existentes entre estos dos tipos de contrato:

7 "Se ha dicho que «la deuda contraída por América con la idea del contrato social es tan enrome que resulta imposible evaluarla», pero lo que importa es que fueron los primeros colonos, no los hombres de la Revolución, quienes «llevaron la idea a la práctica», sin tener noción, desde luego, de ninguna teoría" (Arendt, 1992, p.173). 
el contrato mutuo mediante el cual los individuos se vinculan a fin de formar una comunidad se basa en la reciprocidad y presupone la igualdad; su contenido real es una promesa y su resultado es ciertamente una «sociedad", o "coasociación», en el antiguo sentido romano de societas, que quiere decir alianza. Tal alianza acumula la fuerza separada de los participantes y los vincula en una estructura de poder en virtud de «promesas libres y sinceras». Del otro lado, en el llamado contrato social suscrito entre determinada sociedad y su gobernante, estamos ante un acto ficticio y originario de cada miembro, en virtud del cual entrega su fuerza y poder aislados para constituir un gobierno (ídem, pp.174-175).

En esta extensa cita que aquí transcribimos, y en los párrafos que le siguen, Arendt realiza una compleja distinción conceptual entre la promesa mutua y el contrato social para concluir que

el contrato mutuo que constituye el poder por medio de promesas contiene in nuce tanto el principio republicano, según el cual el poder reside en el pueblo (...) como el principio federal (...) según el cual los cuerpos políticos constituidos pueden combinarse y entrar a formar parte de alianzas duraderas sin que, por eso, pierdan su identidad. Es también evidente que el contrato social, que exige la cesión del poder al gobierno y el consentimiento a su imperio, contiene in nuce tanto el principio de la soberanía absoluta, de un monopolio absoluto de poder «para intimidarles por completo» (Hobbes) (...) como el principio nacional, según el cual debe existir un representante de la totalidad de la nación y donde el gobierno debe incorporar la voluntad de todos los nacionales (ídem, pp.175-176).

Contrato y promesa se distinguen, no sólo en que una es producto de una experiencia política y la otra una mera ficción teórica, sino también teóricamente en tanto que la promesa funda una asociación política en donde poder y libertad están limitados, no por un gobierno, sino porque son limitados en cuanto que son resultado de la acumulación de la fuerza separada de los participantes ${ }^{8}$, mientras que el contrato piensa un poder absoluto -ya que se trata de una sesión de dicha fuerzaque anula la libertad política, es decir, la libertad de acción, de los ciudadanos. La primera se basa en las promesas de los hombres, es decir, en sus acciones, mientras que la segunda en su consentimiento, es decir, el mero asentir de su voluntad. La primera habilita un tipo de asociación política que permita mantener la pluralidad de las organizaciones, mientras que la segunda comanda la unidad del Estado. En estos apurados párrafos Arendt moviliza toda una serie de conceptos políticos a los que, en otras partes de su obra, dedica largas y detenidas páginas a esclarecer: la libertad, la voluntad, el poder, la soberanía, la autoridad. ${ }^{9} \mathrm{Si}$ el desarrollo conceptual sobre

\footnotetext{
8 "el poder político (...) es siempre limitado y dado que el poder y la libertad en la esfera de la pluralidad humana son, de hecho, sinónimos, esto significa también que la libertad política es siempre una libertad limitada" (Arendt, 2002, p.435).

9 Asimismo, entabla en las páginas de Sobre la revolución un diálogo crítico con autores de la teoría política como Hobbes, Rousseau, Maquiavelo, Montesquieu, Tocqueville, que conforman una parte esencial de esta renovación de los conceptos políticos y que aquí, por cuestiones de tiempo y espacio no podremos desarrollar. Hemos abordado algunos de estos diálogos en otros textos (Smola, 2010, 2012).
} 
la promesa puede parecer deficitario en esta obra híbrida, la claridad y simplicidad aparentes que asume la cuestión en su texto generalmente concebido como teórico, La Condición Humana, puede llevar por diversos caminos de comprensión.

En efecto, la promesa aparece en La Condición Humana junto con el perdón en los últimos dos apartados del capítulo $\mathrm{V}$ del libro. Ambos términos se presentan aquí de manera inescindible como una "redención" interna a los problemas derivados de la acción, es decir, a la fragilidad de los asuntos humanos derivados de la imprevisibilidad e irreversibilidad de la acción. Las nociones de promesa y perdón son consideradas capacidades o facultades de los hombres y, como muchos otros temas del libro, parecen estar deshistorizados, tanto política como filosóficamente, es decir, no sólo aparecen separados del análisis de la historia sino también descontextualizadas de las discusiones teóricas y filosóficas. ${ }^{10}$

Asimismo, los conceptos claves relacionados con la promesa como el de poder, libertad, soberanía y voluntad, que Arendt había entretejido en los párrafos que citamos de Sobre la revolución, aparecen aquí de una manera que puede desconcertar al lector. En efecto, lejos de ser abordados con la complejidad a la que nos tiene acostumbrados la autora en su tarea de renovación de los conceptos políticos, son utilizados aquí de manera equívoca, y podría decirse, con cierto descuido. Veamos esto en detalle.

En este texto, el desarrollo sobre la promesa aparece en el capítulo dedicado a la acción. Por lo tanto, lo primero que debemos observar es que el abordaje del mismo está centrado en la perspectiva del actor. Como todos sabemos, el capítulo comienza con los pasajes sobre la pluralidad y la posibilidad-a través de acción y discurso- de revelar la singularidad (uniqueness) del actor, el quien. Este abordaje, conduce a que se indague sobre la forma en que la promesa permite al actor conservar su identidad, en el sentido preciso de que es él quien promete y puede extender islas de certeza (sobre su identidad) en el océano de incertidumbre que es, por definición el futuro (Arendt, 2003, p.256). El futuro es un océano de incertidumbre por la condición de pluralidad, y lo es para el agente que actúa. Así, la promesa permite "al menos parcialmente" una doble "redención" para el actor: frente a la "oscuridad del corazón humano", es decir, de la básica desconfianza de los hombres que nunca pueden garantizar hoy quiénes serán mañana, y a la imposibilidad de pronosticar las consecuencias de un acto en una comunidad de iguales en las que todo el mundo tiene la misma capacidad de actuar. Entonces, la problemática aparece expresada en un lenguaje que resalta la fragilidad de los asuntos humanos en la dimensión del

10 Decimos que parecen estar deshistorizadas y descontextualizadas puesto que aparecen abruptamente en el texto. Sin embargo, como venimos sosteniendo desde el comienzo y tal como veremos a continuación, aquí también -como en Sobre la revolución- estos conceptos se entraman con ciertas experiencias políticas y entran dentro de la discusión que Arendt lleva adelante con la tradición de la filosofía política. 
actor, a diferencia, por ejemplo, de la forma en que surge en Sobre la Revolución en donde lo que se resalta es esa misma fragilidad, pero en una dimensión colectiva e histórica, tematizando las dificultades de fundar instituciones humanas que preserven el espacio de aparición y libertad. ${ }^{11}$

En La condición humana, la promesa es mencionada como un poder conocido a lo largo de nuestra tradición. ${ }^{12}$ En una lectura apresurada, pareciera que Arendt pone su idea de promesa en continuidad con lo que aquella tradición ha pensado sobre ella, relaciona a la promesa con las diversas teorías del contrato, e incluso, con la idea de soberanía. ${ }^{13}$ Esto oscurece las críticas que Arendt realiza más frontalmente en otros textos a la forma en que esa tradición ha leído el contrato y la capacidad de los hombres por formar alianzas. Aquí, en este brevísimo apartado en donde lo que se resalta es nuevamente el punto de vista de la identidad del actor junto con las consecuencias imprevisibles sobre el mundo, estas críticas no aparecen tan claramente planteadas. Sin embargo, es importante reconocer, en las referencias a la tradición, especialmente a Platón, la profundidad de la crítica a la lectura tradicional de la promesa. Nuevamente, el lenguaje teórico de la tradición es el que oculta las experiencias de la promesa. Las que se evocan aquí son experiencias antiguas, como la de Abraham relatada en la biblia, o como la romana en donde alianzas, pactos y leyes estaban en el centro de la acción política.

Es aquí donde toma un sentido pleno la discusión sobre la promesa y su relación con la libertad, indicándonos tal vez un camino a reconstruir para pensar la promesa: “el error básico [de la gran tradición del pensamiento occidental] parece radicar en el identificación de la soberanía con la libertad” (Arendt, 2003, p.254). De esta forma, la soberanía aparece ligada a la tradición de la filosofía, y la figura más destacada es la de Platón. No se trata, como en Sobre la Revolución, de contrastar con la idea de soberanía presente en la teoría política moderna (Rousseau, Hobbes), sino con la que se desprende de la soberanía del yo. Unas a nivel del individuo, otras a nivel del estado, exigen la maestría de todas las consecuencias de los actos humanos y, por lo tanto, eliminan la posibilidad de la libertad. En este punto, La Condición Humana se entreteje al menos con Sobre la Revolución, ¿Qué es la Libertad? y con ¿Qué es la política?. En cuanto a que en ellas se señalan las consecuencias filosóficas, políticas e históricas de pensar la Libertad junto con la Soberanía, y se despliega con más detenimiento, lo que apenas se menciona allí, es decir la posibilidad de una idea

11 Esta distinción, por supuesto, es meramente analítica, puesto que, para Arendt, aún la dimensión subjetiva de la acción es, en sí misma, colectiva, puesto que existen los hombres y no el hombre. Sin embargo, lo que aquí nos interesa es ver cómo cambia el análisis cuando el foco es puesto en una u otra dimensión.

12 "la gran variedad de teorías de contrato desde la época romana atestigua que el poder de hacer promesas ha ocupado el centro del pensamiento político durante siglos." (Arendt, 2003, p.263)

13 Ver infra. 
de libertad como no-soberanía (ídem, p.263). Es en este sentido, que proponemos leer la idea de soberanía limitada que se habilita a través de la posibilidad de hacer promesas, nuevamente como "islas de certeza" que pierden su sentido si se extienden a todo el "terreno del futuro y forman una senda segura en todas direcciones" (ídem, ibídem). De esta forma, el concepto de soberanía, sólo puede ser articulado políticamente bajo la condición de pensar su límite y su precariedad.

La soberanía, que es siempre espuria si la reclama una entidad aislada, sea la individual de una persona o la colectiva de una nación, asume una cierta realidad limitada en el caso de muchos hombres recíprocamente vinculados por promesas. La soberanía reside en la resultante y limitada independencia de la imposibilidad de calcular el futuro, y sus límites son los mismos que los inherentes a la propia facultad de hacer y mantener las promesas. La soberanía de un grupo de gente que se mantiene unido, no por una voluntad idéntica que por algún modo mágico les inspire sino por un acordado propósito para el que sólo son válidas y vinculantes las promesas, muestra claramente su indiscutible superioridad sobre los que son completamente libres, sin sujeción a ninguna promesa y carentes de un propósito (ídem, p.264).

Aquí podemos percibir con claridad la difícil y constante tarea de Arendt en la renovación de los conceptos políticos. En estas pocas líneas, Arendt está resignificando al concepto de soberanía, contraponiendo la idea clásica de soberanía -sea la versión hobbesiana de la soberanía del Leviatán, sea la versión rousseauniana de la voluntad general- a esta otra forma de soberanía limitada, que resulta de la unión de un grupo de gente por un acordado propósito donde sólo son válidas las promesas. ${ }^{14}$

En estos breves párrafos, hemos tratado de demostrar, la fertilidad de pensar el concepto de promesa desde lo desarrollado en Sobre la revolución y en línea con su esfuerzo de renovación de los conceptos políticos. Retomando la hipótesis de Canovan acerca de la forma en que La Condición Humana puede eclipsar ciertas preocupaciones y desarrollos de otros textos intentamos ver qué se ilumina en el concepto cuando es leído bajo la impronta de las preocupaciones más generales que animan su obra. En efecto, como trataremos de ver en nuestro próximo apartado, no se trata únicamente ni principalmente de un interés por la acción en su dimensión subjetiva, irruptiva o destituyente sino también de un interés por su dimensión instituyente, es decir, fundadora de instituciones políticas que resultan imprescindibles para la preservación de la acción y de la libertad.

\section{La fuerza de las promesas y la fragilidad de las instituciones políticas.}

Otro de los múltiples problemas que tiene la lectura de la promesa, que me

14 En este caso, la disputa por el significante "soberanía" es algo tímida y Arendt parece debatirse entre disputar el término o abandonarlo y dejarlo en manos de la teoría de la soberanía, con otros significantes, en cambio, la batalla por recuperar el término para su propia teoría política es más franca. 
gustaría mencionar aquí como último punto de este breve texto, es el que hace referencia a la fuerza de las promesas.

La fuerza que las mantiene unidas [a las personas que se reúnen y actúan de común acuerdo], a diferencia del espacios de aparición en que se agrupan y el poder que mantiene en existencia este espacio público, es la fuerza del contrato o de la promesa mutua (Arendt, 2003, p.264).

Lo que resulta tan problemático de esta afirmación, que se repite a lo largo de su obra es, por un lado, que se contrapone con la idea tantas veces repetida por la propia autora de que, justamente, no existe nada que pueda preservar el poder fuera del poder, ni nada que pueda preservar el espacio de aparición fuera de la acción de aquellos que lo ocupan. Las promesas serían justamente una forma de preservación del espacio de aparición y del poder que surge desde dentro de la acción. Pero entonces, ¿cuál sería exactamente la fuerza de las promesas?

Si retomamos la conocida distinción que Arendt realiza entre fuerza y violencia podemos quedar perplejos:

La Fuerza [force], que utilizamos en el habla cotidiana como sinónimo de violencia, especialmente si la violencia sirve como medio de coacción, debería quedar reservada en su lenguaje terminológico, a las "fuerzas de la Naturaleza" o a la fuerza de las circunstancias («force des choses»), esto es, para indicar la energía liberada por movimientos físicos o sociales (Arendt, 1970, pp.44-45).

La razón de nuestra confusión reside en que aquí el acento está puesto en la distinción entre Poder y Violencia, entendiendo que sólo el poder puede ser propiedad de un grupo o comunidad y no existe aisladamente. La potencia [strenght] es propiedad de una entidad singular o individual, y la violencia, siendo instrumental, puede ser monopolizada por un grupo o un individuo. La fuerza, por el contrario, parece no tener sujeto y estar reservada para fenómenos naturales más bien disruptivos. Sin embargo, en Sobre la revolución resulta inteligible la idea de fuerza como aquello que resulta de las promesas que vinculan a los hombres, creando así una nueva estructura de poder. El poder es efímero y sólo surge cuando los hombres están unidos, la fuerza de las promesas puede perdurar en esta estructura que se entrama a través de ellas. Como señala Arendt:

Tras todo esto, hay toda una concepción acerca de la naturaleza del poder humano. A diferencia de la fuerza [strenght], el poder sólo aparece allí donde los hombres se reúnen con el propósito de realizar algo en común, y desaparecerá cuando por la razón que sea, se dispersen o se separen. Por lo tanto, los vínculos y las promesas, la reunión y el pacto son los medios por los cuales el poder se conserva; siempre y cuando los hombres logren mantener intacto el poder que brotó de su seno durante el curso de una acción o empresa determinada, puede decirse que se encuentran en pleno proceso de fundación, de constitución de una estructura secular estable que dará albergue, por así decirlo, a su poder colectivo de acción. (ídem, pp.179-180, nuestras cursivas) 
La fuerza [force] de las promesas es la reificación del acto de fundación en instituciones jurídicas (Correia, 2014, p.166). Es a través de ellas, de la posibilidad de "promulgar, constituir y elaborar, cuando la ocasión lo requiera, tantas leyes, ordenanzas, actos, constituciones y oficios justos y equitativos cuantos estime necesarios la mayoría y convengan al bienestar general de la colonia" (Pacto del Mayflower, citado por Arendt, 1992, p.177) que se teje esta nueva estructura jurídica que protege el espacio de la acción. Así, se despliega aún otra dimensión de la renovación de los conceptos políticos de Arendt, esto es, el concepto de ley. Si Arendt pensaba que la ley podía ser el refugio y la protección de la libertad, era a condición de modificar radicalmente lo que nos había enseñado el iusnaturalismo. Arendt sugiere buscar el significado de la ley en la experiencia de los romanos, tal como lo había rescatado Montesquieu:

las leyes, que, siguiendo a Montesquieu, transforman a los individuos libres y sin ley en ciudadanos, no son los Diez Mandamientos de Dios o la voz de la conciencia o la lumen rationale que ilumina a todos los hombres, sino rapports, "relaciones" establecidas por los hombres y que, en la medida en que conciernen a los mudables asuntos de los hombres mortales - a diferencia de la eternidad divina o la inmortalidad del cosmosdeben estar "sometidas a todos los accidentes que ocurran, y variar a medida que cambian las voluntades de los hombres" (Arendt, 2002, 367).

De esta forma, la fortaleza (y la fragilidad) de esta estructura de poder, reside en que la misma debe ser permeable a su cuestionamiento constante por medio de las acciones y de las promesas de los hombres que constituyen el cuerpo político. Como señala Adriano Correia:

Luego de la fundación, no debe cesar la praxis y comenzar la gestión, puesto que la razón de ser de la institución de las comunidades políticas no es, para Arendt, la administración de la vida social, sino la preservación de un espacio público de participación política en la cual la libertad pueda aparecer. La razón de ser de la fundación es la conservación, via la institucionalización, de la praxis originaria que ha gestado el poder. Por eso, Arendt jamás identificaría el ejercicio del poder político en las instituciones de una determinada comunidad política con una relación de dominación. Es más, no consideraría legítimo a ningún poder político desligado de su praxis originaria, como tampoco consideraría vigorosa a ninguna comunidad política que no fuese capaz de reificar esa práctica en instituciones jurídicas capaces de actualizarla permanentemente. (Correia, 2014, p.166 y nuestras cursivas).

De esta forma, la fundación de instituciones políticas tiene el doble sentido de estabilizar el comienzo y de permitir -incluso incentivar- el cambio y la transformación de las instituciones.

El concepto romano de autoridad indica que el acto de fundación desemboca inevitablemente en la estabilidad y la permanencia, y la autoridad, en este contexto, no es otra cosa que una clase de "aumento" necesario, en virtud del cual todas las innovaciones y cambios se religan a la fundación a la cual, al mismo tiempo, aumentan e incrementan. De este modo, las enmiendas a la Constitución aumentan e incrementan 
las fundaciones originales de la República americana; no es necesario decir que la autoridad de la Constitución americana reside en su capacidad originaria para ser enmendada y aumentada. Esta idea de coincidencia entre fundación y conservación en virtud del aumento -la interconexión existente entre el acto "revolucionario" de dar origen a algo enteramente nuevo y el cuidado conservador que protegerá este nuevo origen a través de los siglos- estuvo profundamente enraizada en el espíritu romano y puede hallarse en casi todas las páginas de la historia de Roma (Arendt, 1992, pp.208209).

Arendt toma allí inspiración de la más antigua tradición republicana, que considera la duración como una permanencia en el movimiento. Es en este sentido que Arendt rescata la importancia de separar Autoridad y Poder. Sólo una autoridad que pueda ser concebida separadamente del poder (aunque en realidad haya surgido de él) puede proveer la estabilidad necesaria para el cambio. Para decirlo en términos de Arendt, sólo una institución humana, que no se legitime en las leyes de la naturaleza, de la historia o de la nación; sólo una institución fundada por un acto político (es decir, por una acción), puede a la vez "construir un mundo" donde los hombres puedan actuar, y soportar los avatares propios de la pluralidad y la natalidad, es decir, soportar el hecho de que los hombres son siempre un nuevo comienzo y nunca sabemos el resultado de aquello que comenzamos.

\section{Algunas conclusiones para la lectura de Sobre la revolución.}

En estas páginas, hemos tratado de acercar una lectura de Sobre la revolución que pusiera el énfasis en su esfuerzo por la renovación de los conceptos políticos y que pusiera en valor la originalidad de las ideas teóricas que Arendt vierte en este texto. Así, tratamos de responder a las lecturas que sólo hacen hincapié en la crítica que Arendt realiza del Estado-Nación y a la Teoría de la Soberanía argumentando que este anti-estatalismo de la autora no significa un desinterés por la fundación de instituciones políticas estables.

Es necesario comprender el interés de Arendt por la ley, las instituciones y las organizaciones políticas populares debido a que nos muestran otra dimensión de su pensamiento que es sumamente importante, sobre todo para nuestras las lecturas latinoamericanas. En efecto, si bien es cierto que Arendt puede ser movilizada para pensar los movimientos populares que irrumpen en el espacio político-institucional como expresión de la libertad y de la acción política. Si bien es así, como señala Tassin, que el pueblo es libre, siempre y cuando renuncie al principio de Soberanía. No es menos cierto que pueblo, para Arendt, no es solo o únicamente el pueblo que se manifiesta espontáneamente sin organización y contra las instituciones. Pueblo libre es, para Arendt, un pueblo que se organiza políticamente, que se une a través de promesas en "cuerpos políticos" que debaten, promulgan leyes, se asocian con 
otras organizaciones y construyen, desde ahí, una estructura de poder.

De hecho, contrariamente a lo que se ha interpretado de este texto, el interés principal de Arendt, en lo que respecta a la acción revolucionaria, se centra en la organización del pueblo. Así, llega a sostener que el problema más grande que la revolución francesa debió afrontar fue que "El pueblo en Francia, le peuple en el sentido de la Revolución, no estaba ni organizado ni constituido" (Arendt, 1992, 185). Por el contrario, la virtud y la mayor suerte de la revolución Americana fue que el pueblo ya se encontraba organizado en cuerpos políticos autónomos que pudieron unirse sin perder su identidad. Esta organización les brindaba un espacio de acción, y por lo tanto de libertad.

También en sentido contrario a lo que la mayoría de las lecturas de este texto suelen interpretar, la conclusión de Arendt es que ambas revoluciones fracasaron en su intento de fundar la libertad y de preservar el espíritu revolucionario. La "preferencia” de Arendt con la revolución americana (si fuera lícito hablar así) sería únicamente respecto a lo que la misma puso en evidencia, y que el lenguaje de la teoría política ocultó. Esto es, la experiencia política de un nuevo tipo de poder y una nueva estructura que pudiera albergarlo. Arendt, por otra parte, también observa esa experiencia en la revolución francesa, durante el breve lapso de la Comuna. ${ }^{15}$ Lo que ocurrió, en ambas revoluciones, es que no logró institucionalizarse "un espacio donde pudiese ejercerse esta libertad" (Arendt, 1992, p.243). Allí, tal vez se encuentre la indicación más potente para una nueva teoría política aún no escrita y la crítica más potente a la política contemporánea. Esta última, no se limita a mostrar los efectos devastadores para occidente de confundir violencia con autoridad, poder con dominación. La crítica de Arendt se extiende a la democracia liberal representativa, a la que ataca con dureza y profundidad. En este sentido señala, “o la libertad política en su acepción más amplia, significa el derecho a «a participar en el gobierno», o no significa nada” (ídem, p.225).

\section{Referencias}

Abensour, M. (2006). Hannah Arendt contre la philosophie politique?. París: Sens\&Tonka.

Arendt, H. (1970). On Violence. Nueva York: Harcourt, Brace\&Court.

Alianza.

.(1992 [1963]). Sobre la revolución. Traducción de Pedro Bravo. Madrid:

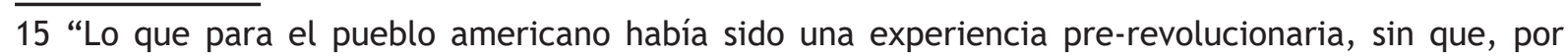
tanto, requiriera fundación ni reconocimiento formal, fue en Francia el resultado espontáneo e inesperado de la propia Revolución. Las famosas cuarenta y ocho secciones de la Comuna de París tuvieron su origen en la falta de cuerpos populares legalmente constituidos que eligiesen representantes y enviasen delegados a la Asamblea Nacional” (Arendt, 1992, pp.248 y ss.). 
.(1997[1963]). "Seule demeure la langue maternelle". In: Hannah Arendt, la tradition caché. Le Juif comme paria. Traducción de Silvie CurtineDenamy. París: Christian Bourgois Éditeur.

.(2002 [1978]). La vida del espíritu, Segunda Parte: La Voluntad. Traducción de Carmen Corral y Fina Birulés. Buenos Aires: Paidós.

.(2003 [1958]). La condición Humana. Traducción de Ramón Gil Novales. Buenos Aires: Paidós.

Bacci, C. (2010). Recepción de las obras de Hannah Arendt en la Argentina: Lecturas e intervenciones intelectuales (1942-2000), (Tesis de Maestría). Universidad de Buenos Aires, Facultad de Ciencias Sociales, Ciudad Autónoma de Buenos Aires.

Canovan, M. (1992). Hannah Arendt. A reinterpretation of her political thought. Cambridge: Cambridge University Press.

Correia, A. (2014). Hannah Arendt e a modernidade. Política, economía e a disputa por uma fronteira. Rio de Janeiro: Forense Universitária.

Di Pego, A. (2014). La modernidad en cuestión: Totalitarismo y sociedad de masas en Hannah Arendt. La Plata: EDULP.

Forti, S. (2001). Vida del espíritu y tiempo de la polis. Hannah Arendt entre filosofía y política. Madrid: Universitat de València.

Habermas, J. (1977). Hannah Arendt's communications concept of power. Social Research, 44, pp.3-23.

Hilb, C. (1990). Promesa y política. Promesas traicionadas y transición democrática. Buenos Aires: Universidad de Buenos Aires, Facultad de Ciencias Sociales.

Hunziker, P. (2015). Filosofía, Política y Platonismo: investigación sobre la lectura arendtiana de Kant, en el marco de su reflexión crítica sobre la herencia filosófica, durante los años cincuenta y sesenta (Tesis de doctorado). Universidad Nacional de Córdoba, Facultad de Filosofía y Humanidades, Córdoba.

Lechner, N. (1990). Los patios interiores de la democracia. Subjetividad y política. México, DF: Fondo de Cultura Económica.

Lefort, C. (2001 [1985]). "Hannah Arendt et la question du politique" (Conferencia pronunciada el 5 de marzo de 1985). In: Essais sur le politique. XIXe-XXesiècles. Paris: Seuil.

Lesgart, C. (2003). Usos de la transición democrática. Ensayo, ciencia y política en la década del 80. Rosario: Homo Sapiens.

Smola, J. (2010). Arendt lectora de Rousseau. Revista Dois Pontos,7(4), pp.53-63.

. (2012) "Arendt lectora del contractualismo. El contrato y la fundación política moderna.". In: Claudia Bacci, Paula Hunziker y Julia Smola (eds.) Lecturas de Arendt. Diálogos con la literatura, la filosofía y la política. Córdoba: Ed. Brujas.

Ricoeur, P. ([1983] 1994). “Préface”. In: Arendt, H. Condition de l' home moderne. Paris: Calmann-Lévy.

Tassin, E. (2007). “Le peuple ne veut pas”. In: AnneKupiec [et.al.]. Hannah Arendt, 
Julia Gabriela Smola

crises de l'état-nation. Paris: Sens\&Tonka.

Taminiaux, J. (2001). “¿'Performatividad’ y ‘grecomanía’?”. In: Richard J. Berenstein [et. al]. Hannah Arendt. El legado de una mirada. Madrid: Sequitur.

Young-Bruehl, E. (1999, [1982]). Hannah Arendt. Biographie. Traducción de. Joël Roman y Etienne Tassin. Paris: Calmann-Levy.

Recebido em: 06.05.2016

Aceito em: 07.08.2016 